\title{
Respectful resection to enhance the armamentarium of mitral valve repair: Is less really more?
}

Harold G. Roberts, MD, J. Scott Rankin, MD, Lawrence M. Wei, MD, Chris C. Cook, MD, Muhammad Salman, MD, and Vinay Badhwar, MD

From the Department of Cardiovascular and Thoracic Surgery, West Virginia University, Morgantown, WVa.

Disclosures: Dr Badhwar serves as a consultant for Tendyne, operated by Abbott (uncompensated). Authors have nothing to disclose with regard to commercial support.

Received for publication June 30, 2018; accepted for publication July 2, 2018; available ahead of print Aug 11, 2018.

Address for reprints: Vinay Badhwar, MD, Department of Cardiovascular \& Thoracic Surgery, West Virginia University, 1 Medical Center Dr, Morgantown, WV 26506-8059 (E-mail: vinay.badhwar@wvumedicine.org).

J Thorac Cardiovasc Surg 2018;156:1854-5

$0022-5223 / \$ 36.00$

Copyright $@ 2018$ by The American Association for Thoracic Surgery

https://doi.org/10.1016/j.jtcvs.2018.07.011

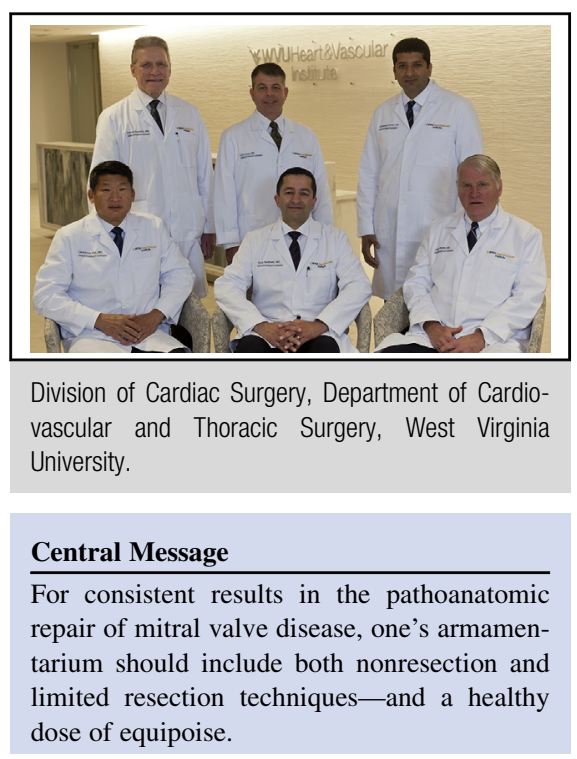

See Article page 1856.
Professor Alain Carpentier introduced the foundational principles of incorporating posterior leaflet height reduction as part of comprehensive mitral valve reconstruction for diffuse myxomatous degeneration. ${ }^{1}$ For 25 years, many have channeled those principles through technical modifications attempting to enhance reproducibility and minimally invasive applicability while holding to established standards of $<1 \%$ mortality and excellent durability. Dreyfus and colleagues ${ }^{2}$ elegantly outline a 10 -year experience with mitral reconstruction focused on posterior leaflet management in degenerative disease. Of 441 patients, 376 had their posterior leaflet managed by limited or focal resection and semirigid annuloplasty. The limited resection techniques consisted of either focal triangular resections or a reductive resection of excess $\mathrm{P} 2$ flail segments and secondary chordal transfer, sometimes referred to as the haircut valvuloplasty. ${ }^{3,4}$ The results were exemplary, with a $100 \%$ repair rate and trivial morbidity and mortality. Longitudinal echocardiographic results demonstrated excellent durability and a high freedom from clinically significant mitral regurgitation. Dreyfus and colleagues ${ }^{2}$ provide an insightful commentary on how much and when to resect. They infer that limited resection techniques may be superior to other resection or nonresection techniques.

Instead of interpreting outstanding results of a preferred technique by a surgeon as superior to others, one should incorporate the collective experience of many when approaching any operation. This is particularly applicable to mitral valve repair for degenerative disease. As all surgeons are well aware, the restoration of posterior leaflet height and coaptation with polytetrafluoroethylene neochordal resuspension methods have enjoyed similarly excellent outcomes, even with minimally invasive application. ${ }^{5-7}$ Although many would passionately attest that a purely nonresection technique reproducibly addresses all manner of degenerative mitral pathologies, including Barlow's syndrome, ${ }^{6}$ some polar antagonists have argued that the technique variability of neochordal creation may limit reproducibility, may not effectively reduce posterior height when systolic anterior motion (SAM) is predicted, and may not preserve as much leaflet mobility as resection techniques. ${ }^{2}$ As always, the truth exists somewhere between the poles of opinion. In fact, what appears to be known is that both neochordal and limited resection techniques are nearly equivalent in their preservation of leaflet mobility compared with traditional quadrangular resection techniques. ${ }^{8}$ Recent meta-analyses illustrate the evolving trend to apply neochordal techniques more frequently, but the precision of pathophysiologic and technique reporting limits any conclusions of superiority of 1 method over another. 9,10 Because the spectrum and presentation of myxomatous mitral disease can span from a focal P2 ruptured chord to diffuse multiscallop bileaflet involvement with mitral annular calcification, it is 


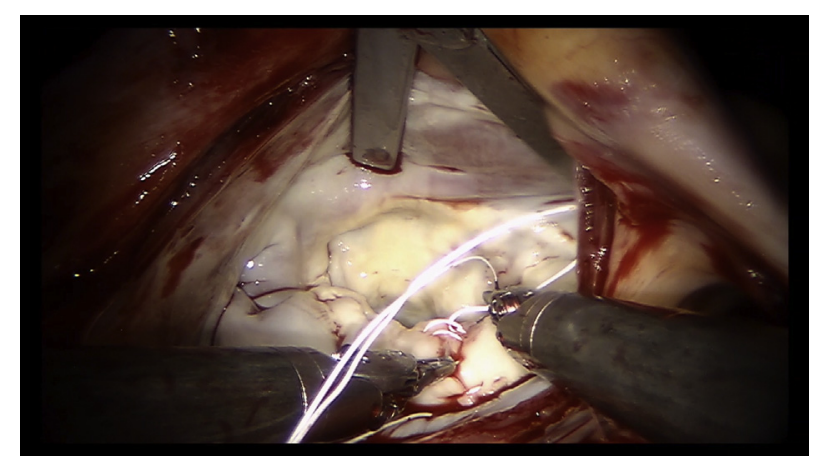

VIDEO 1. Robotic respectful resection technique to address diffuse posterior leaflet prolapse in the setting of significant preoperative echocardiographic predictors of systolic anterior motion. Limited triangular posterior leaflet resection is followed by supported polytetrafluoroethylene suture reapproximation and flexible annuloplasty. Video available at: https://www. jtcvs.org/article/S0022-5223(18)31848-8/fulltext.

unlikely that a 1-size-fits-all strategy would provide consistent results for most surgeons.

Although the neochord technique should forever have its place in the armamentarium of mitral surgeons, so too should the principle of resecting with respect ${ }^{10}$ or judiciously resecting when necessary. ${ }^{2}$ These perspectives have helped reproducibly secure durable outcomes for open as well as robotic platforms. ${ }^{11,12}$ For our open as well as robotic approaches, we follow the principle of pathoanatomically targeted techniques that draw from all methods. When faced with diffuse bileaflet disease or forme fruste degeneration of the posterior leaflet combined with elevated echocardiographic predictors of SAM (ie, acute aortomitral angle or narrow coaptation to septal distance), we favor more resection techniques. For focal disease of either leaflet, we favor more neochordal techniques or focal resection. When faced with diffuse posterior leaflet prolapse in combination with significant SAM predictors, we have frequently used what we have institutionally referred to as our respectful resection technique (Video 1). This involves a posterior leaflet triangular resection followed by a single polytetrafluoroethylene suture anchored in the papillary muscle that is used to reapproximate the leaflet in a 2-layer running fashion. This serves to reduce posterior leaflet height, consistent with Carpentiesian principles, while providing additional support for augmented effect.

As the debate continues over the ever-elusive equipositional sweet spot for mitral valve repair technique for degenerative disease, 2 central themes emerge: neochordal and resection methods should be applied based on disease-specific pathoanatomic complexity within the experience and comfort of the surgeon, and less may indeed be more.

\section{References}

1. Carpentier A. Cardiac valve surgery-the "French correction" J Thorac Cardiovasc Surg. 1983;86:323-37.

2. Dreyfus GD, Dulguerov F, Marcacci C, Haley SR, Gkouma A, Dommerc C, et al. "Respect when you can, resect when you should": a realistic approach to posterior leaflet mitral valve repair. J Thorac Cardiovasc Surg. 2018;156: 1856-66.

3. Dreyfus GD, Corbi P, Rubin S, Aubert S. Posterior leaflet preservation in mitral valve prolapse: a new approach to mitral repair. J Heart Valve Dis. 2006;15: 528-30.

4. Chitwood WR Jr. Haircut mitral valve repair: posterior leaflet-plasty. Ann Cardiothorac Surg. 2015;4:387-92.

5. David TE, Armstrong S, Ivanov J. Chordal replacement with polytetrafluoroethylene sutures for mitral valve repair: a 25-year experience. J Thorac Cardiovasc Surg. 2013;145:1563-9.

6. Lawrie GM, Zoghbi W, Shah D, Ben Zehry Z, Earle N, Earle E. One hundred percent repairability of degenerative mitral regurgitation: intermediate-term results of a dynamic engineered approach. Ann Thorac Surg. 2016;101:576-83.

7. Seeburger J, Falk V, Borger MA, Passage J, Walther T, Doll N, et al. Chordae replacement versus resection for repair of isolated posterior mitral leaflet prolapse: à ègalité. Ann Thorac Surg. 2009;87:1715-20.

8. Padala M, Powell SN, Croft LR, Thourani VH, Yoganathan AP, Adams DH. Mitral valve hemodynamics after repair of acute posterior leaflet prolapse: quadrangular resection versus triangular resection versus neochordoplasty. $J$ Thorac Cardiovasc Surg. 2009;138:309-15.

9. Mazine A, Friedrich JO, Nedadur R, Verma S, Ouzounian M, Jüni P, et al. Systematic review and meta-analysis of chordal replacement versus leaflet resection for posterior mitral leaflet prolapse. J Thorac Cardiovasc Surg. 2018;155: 120-8.e10.

10. Antunes MJ. Isolated posterior mitral leaflet prolapse: resect, respect, or resect with respect? J Thorac Cardiovasc Surg. 2018;155:129-30.

11. Tatum JM, Bowdish ME, Mack WJ, Quinn AM, Cohen RG, Hackmann AE, et al Outcomes after mitral valve repair: a single-center 16-year experience. J Thorac Cardiovasc Surg. 2017;154:822-30.e2.

12. Coyan G, Wei LM, Althouse A, Roberts HG, Schauble D, Murashita T, et al. Robotic mitral valve operations by experienced surgeons are cost-neutral and durable at 1 year. J Thorac Cardiovasc Surg. 2018;156:1040-7. 